\title{
Short-term multi horizons forecasting of solar irradiation based on artificial neural network with meteorological data : Application in the north-west of Senegal
}

\author{
Willy Magloire Nkounga, \\ Univ. Savoie Mont Blanc, \\ SYMME, F-74000 Annecy, France \\ Laboratoire Eau-Energie- \\ Environnement-Procédés Industriels (LE3PI) \\ École Supérieure Polytechnique (ESP) \\ Université Cheikh Anta Diop (UCAD) \\ Email: willy-magloire.nkounga@univ-smb.fr, \\ welly-magloire.nkounga@ucad.edu.sn
}

\author{
Mouhamadou Falilou Ndiaye \\ LE3PI-ESP-UCAD \\ Email: mouhamadouf.ndiaye@ucad.edu.sn
}

\section{Oumar CISSE \\ LE3PI-ESP-UCAD \\ Momadou Bop \\ LE3PI-ESP-UCAD}

Email: oumar.cisse@univ-thies.sn

Email: mamadou1.bop@ucad.edu.sn
Françoise Grandvaux

Univ. Savoie Mont Blanc, SYMME, F-74000 Annecy, France

Email: francoise.grandvaux@univ-smb.fr

\section{Mamadou Lamine Ndiaye LE3PI-ESP-UCAD}

Email: mamadoulamine.ndiaye@ucad.edu.sn
Keywords-solar irradiation, neural network, levenbergmarquardt, multi horizons, forecasting.
Laurent Tabourot

Univ. Savoie Mont Blanc, SYMME, F-74000 Annecy, France

Email: laurent.tabourot@univ-smb.fr

\section{INTRODUCTION}

Renewable energies have experienced significant growth for several decades due to their positive impact on the environment [1]. In the most developing countries, electrical energy is largely supplied by power grids and associated power plants that are often inefficient and unreliable due to poor maintenance [2]. One of the economic consequences is the low rate of rural electrification, the high cost per $\mathrm{kWh}$ in rural areas and the unavailability of electricity for the income-generating activities. To address these issues, the use of renewable energy is an important part of the solution. To this end, several works are proposed in the literature in order to exploit the renewable resource: wind and solar power potential assessment [2], sizing of solar panels and wind turbines [3], control and command [4], energy demand forecasting [5] and available energy forecasting. In this work, we are interested in the last category.

Energy forecasting offers the possibility to guarantee its availability in order to meet current and future needs. 
The works [6] has classified the forecasting models into several horizons: the short term ([second - $06 \mathrm{~h}]$ ), the medium term ( ]06h-24h]) and the long term (1 week and more). We are interested in forecasting solar irradiation over the short term.

Forecasting models are classified into three main categories [7]: physical, statistical and intelligent models. A comparative studies of these models indicate that, artificial intelligence is very suitable for forecasting the solar energy resource and allows to obtain good results [1]. The most used artificial intelligence models are: artificial neural network (ANN), support vector machine and fuzzy logic. The ANN is ranked as the best and most used forecasting model [8]. In this work, the ANN is used for forecasting solar irradiation over several short-term horizons.

The artificial neural network has the particularity of managing a large volume of data. Its four basic principles are [6] : the network typology, the type of association between input and output variables, the data training method and the forecasting ouptut presentation. In the literature, several methods are used to select the network typology needed to train the ANN model: system for automated learning operative networks (Salmon) [9], Bayesian method [10], R development core team [11] and the Waikato software for knowledge analysis (Weka) [12]. In addition to providing the network typology and choosing the variables of interest, Weka offers the possibility to choose the number of hidden layers for ANN training. ANN performance is evaluated according to several criteria [13] : correlation coefficient (R), root mean square error (RMSE), normal root mean square error(nRMSE), mean bias error (MBE), mean absolute percentage error (MAPE) and statistical time indicator (t-statistic).

The objective of this work is to establish and classify short-term forecasting models of solar irradiation along several horizons in north-western Senegal. The horizons vary from 0.5 hour to six hours. Each horizon is validated based on its performance criteria. The results will help address the problems of energy demand and production in Senegal. Indeed, $75 \%$ of the population in Senegal lives in rural areas and more than $50 \%$ has no access to electricity. In order to respond to the electrification problems, several solar power plants have been built in recent years, but are struggling to balance energy production with user energy demand; a majore causes of this shortage is the intermittency of the solar resource.
To date, very few forecasting models have been developed in Senegal to address the problem of solar resource's intermittency. The short-term forecasting models over several time horizons, proposed in this paper, will complete the existing works.

The works [14] has developed a short-term forecasting model for wind potential in the north-west of Senegal using linear prediction, with a correlation coefficient of 0.86. Solar irradiation short-term forecasting, applied to north-western Senegal is developed in [15] with a correlation coefficient of 0.99 ; the authors have limited the horizon to $10 \mathrm{~min}$. To complete this limit, we propose forecasting models for short-term horizons from 30 minutes to 06 hours. Using Kalman filters, solar potential forecasting is carried out over a 20-minute horizon in Dakar [16] ; the results are obtained with a normal quadratic error of $4.8 \%$. The works [17] studied short-term forecasting of solar potential in Dakar using the autoregressive moving average (ARMA) method; annual meteorological data from the "École Supérieure Polytechnique Dakar" were used; the results show a correlation coefficient of 0.97 and a root mean square error (RMSE) of 0.629. To solve the problem of energy demand in Senegal, electricity forecasting on one hour horizon is proposed in the works [18]. The data used are the times of sunny days and hourly weather data. The results are obtained with a correlation coefficient of 0.9. Using $\mathrm{R}$ Software and satellite data, the work [19] carried out solar irradiation forecasting in several regions of Senegal: Dakar, Saint-Louis, Tambacounda and Ziguinchor. The forecasting performance showed a mean square error of $20 \%$. The solar potential forecasting over a 20 minute horizon in Dakar using solar irradiation data on the one hand, and the solar irradiation, humidity and temperature on the other hand is carried out using the Kalman filter in [20]. The results are obtained with a normal root mean square error of $4.9 \%$ and $4.8 \%$ respectively.

The above forecasting models, developed in Senegal are based on a single time horizon, which do not leave investors and decision-makers the option of choosing the energy forecasting horizons corresponding to users demand. To make an additional contribution to the existing works, we propose in this paper:

- the different meteorological variables and their influence on short-term forecasting accuracies;

- Twelve short-term forecasting models with horizons ranging from 30 minutes to six hours. It is the originality of this study. It will complete 
our previous work in which the horizon was limited to 10 minutes. It will allow investors and solar power plants owners to choose the forecasting horizons by taking into account the energy demand, the availability and the capacity of the measurement infrastructures collecting and storing the data.

The rest of the paper is organized as follows: section 2 presents the study environment and the data presentation. Section 3 describes and presents the method; section 4 is devoted to the results and discussion. The final section presents the conclusion and perspectives.

\section{STUDY ENVIRONMENT AND DATA PRESENTATION}

The studied environment is located in the northwest of Senegal. This environment has a strong solar potential ranging from $3756 \mathrm{Wh} / \mathrm{m}^{2} /$ day in December to $6420 \mathrm{Wh} / \mathrm{m}^{2} /$ day in April. The data are from the Gandon site, located between $15^{\circ} 26^{\prime} 50^{\prime \prime}$ of the northern altitude and $16^{\circ} 26^{\prime} 49^{\prime \prime}$ eastern longitude. The meteorological data used are measured and averaged in 10 min steps; they are: number of the day (Dn), time of measurement $(\mathrm{h})$, maximum $(\mathrm{Tm})$ and average $(\mathrm{T})$ temperature, maximum $(\mathrm{Hm})$ and average $(\mathrm{H})$ relative humidity, maximum (Em) and average (E) solar irradiation, atmospheric pressure $(\mathrm{P})$. These data are presented and detailed in our previous work [15].

\section{Methods}

The synoptic diagram used for solar irradiation forecasting is shown in Figure 1

\section{A. Selection of the interest variables and the hidden} layers number

The variables of interest are selected using Weka software. It is a software developed by the University of Waikato, adapted for machine learning and data mining. It helped to establish:

- the contribution of each variable on the solar irradiation forecasting accuracy over the $\Delta T$ horizon,

- the contribution of the variables combination on solar irradiation forecasting accuracy over the $\Delta T$ horizon,

- the choice of the hidden layers number.

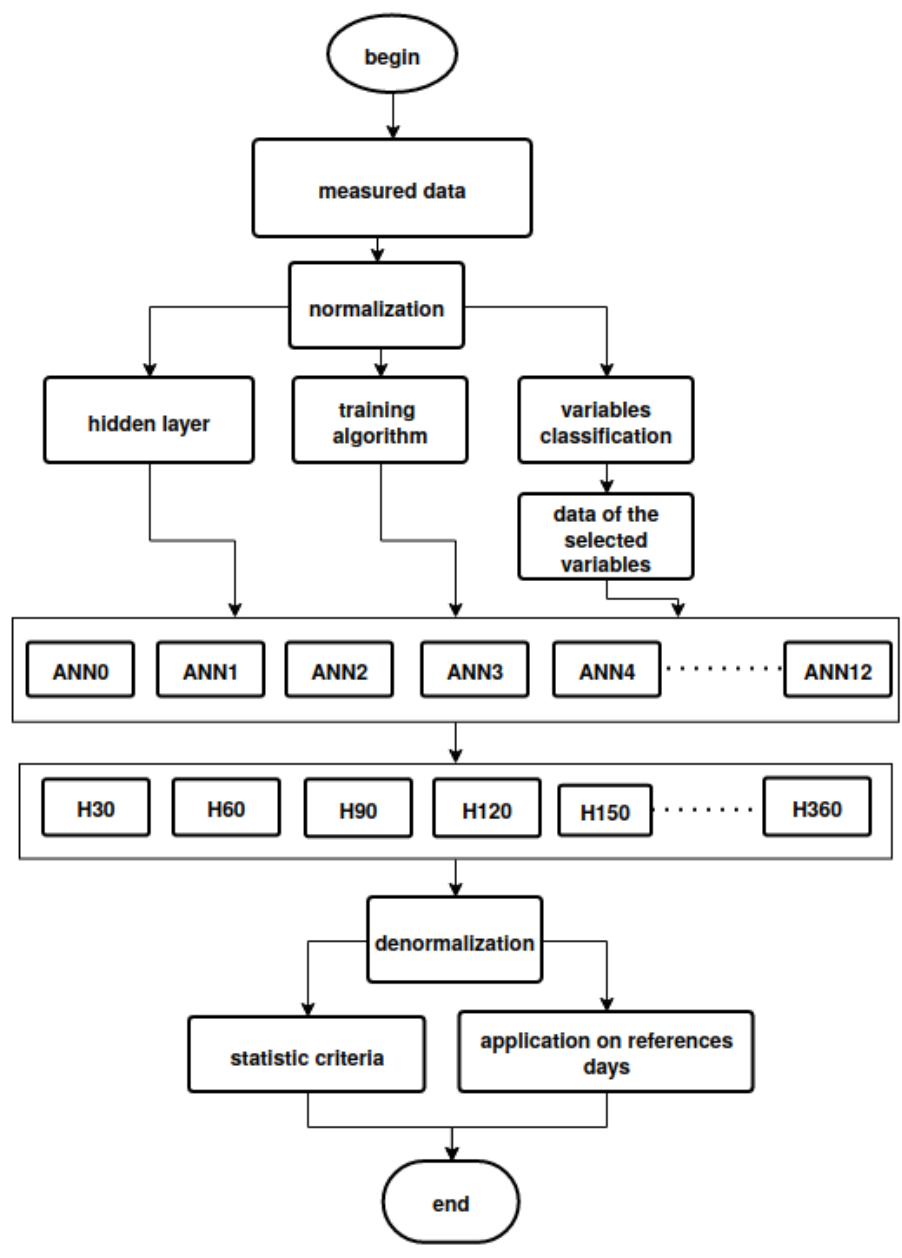

Figure 1. ANN synoptic diagram

\section{B. data normalization and denormalization}

Large input values associated with small values can compromise the learning step leading to local sub-optimization [21]. To avoid this problem, authors [22] recommend to use nomalized data for training ANN. This method consists in improving the ANN performance and convergence [9].

Equation (1) is used for data normalization:

$x: \quad$ the measured variable

$y \quad$ the normalized value of the measured variable

$x_{\max }$ the measured variable's maximum value

$x_{\min }$ the measured variable's minimum value

$y_{\min }$ the normalized variable's minimum value

$y_{\max }$ the normalized variable's maximum value

$$
y=\frac{\left(y_{\max }-y_{\min }\right)\left(x-x_{\min }\right)}{\left(x_{\max }-x_{\min }\right)}+y_{\min }
$$

After training the artificial neural network model, the data are denormalized using equation(2). Denormalization consists in bringing the normalized data to the 
normal values.

$$
x=\frac{\left(x_{\max }-x_{\min }\right)\left(y-y_{\min }\right)}{\left(y_{\max }-y_{\min }\right)}+x_{\min }
$$

\section{Artificial neural network}

The ANN typology used is the feed-forward multilayer perceptron neural network. Its internal configuration as well as the training equations (the levenbergmarquardt agorithm) are presented in [15]. The ANN architecture and the training flowchart for each horizon are presented respectively on Figure 2 and Figure 3

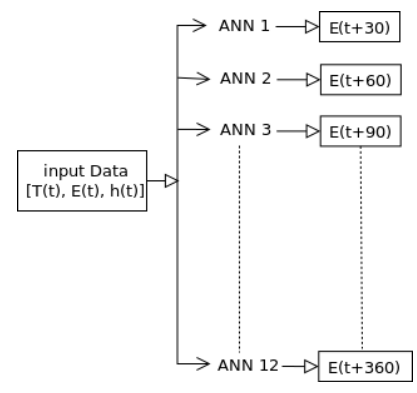

Figure 2. multi horizons forecasting

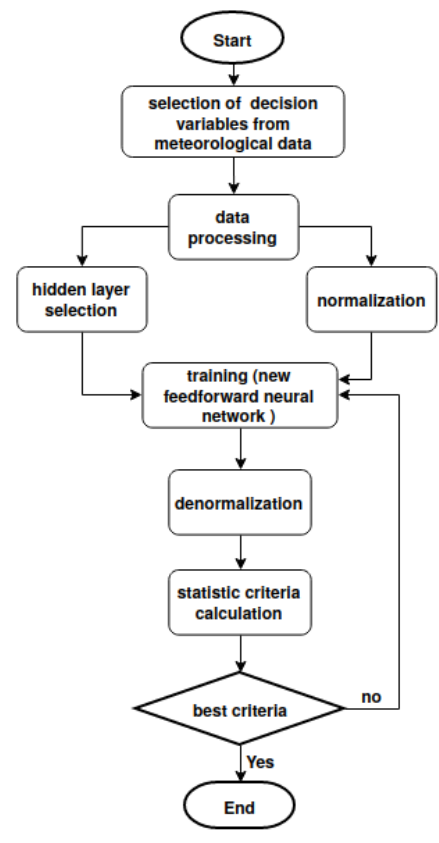

Figure 3. ANN training

\section{ANN STATISTICAL CRITERIA}

ANN performance are calculated using Eq.(3) [13]; Eq.(4),Eq.(5) [21]; Eq.(6),Eq.(7) [13].

$x_{i} \quad$ the $i^{\text {th }}$ measured data

$\hat{x}_{i} \quad$ the $i^{\text {th }}$ forecasted data

$E(x)$ the average of the test data

$N \quad$ total number of test data

$$
\begin{gathered}
R^{2}=1-\frac{\sum_{i}\left(x_{i}-\hat{x_{i}}\right)^{2}}{\sum_{i}\left(x_{i}\right)^{2}} \\
R M S E=\sqrt{\frac{\sum_{i}\left(x_{i}-\hat{x_{i}}\right)^{2}}{N}} \\
n R M S E=\frac{R M S E}{E(x)}
\end{gathered}
$$

$$
\begin{gathered}
M B E=\frac{1}{N} * \sum_{i}\left(\hat{x}_{i}-x_{i}\right) \\
t-\text { statistic }=\sqrt{\frac{(N-1) M B E^{2}}{R M S E^{2}-M B E^{2}}}
\end{gathered}
$$

\section{A. reference days}

A reference day is calculated for each month of the year. Forecasting performance is evaluated for each reference day. This latter is defined as the closest to the monthly average data [14]. Let $E_{i, j, h}$ be the solar irradiation measured at time $h$ of day $j$ in the month $i$.

$h$ the time corresponding to the measurement of the day $j$;

$j$ the number of the day in the month $i$

$i$ the number of the month in the year ;

$h \in\{10,20, \ldots, 1440\}$

j $\epsilon\{1,2, \ldots, 31\}$

$i \epsilon\{1,2, \ldots, 12\}$.

The solar irradiation $E_{i, j}$ of the day $j$ in the month $i$ is given by equation (8)

$$
E_{i, j}=\left[E_{i, j, 10}, E_{i, j, 20}, \ldots, E_{i, j, 1440}\right]^{T}
$$

The average value of solar irradiation $\bar{E}_{i, h}$ at time $h$ is calculated by the equation (9)

$$
\bar{E}_{i, j}=\sum_{j=1}^{N_{i}} \frac{E_{i, j, h}}{N_{i}}
$$

the average day $\bar{E}_{i}$ of the month $i$ is defined by equation 10

$$
\bar{E}_{i}=\left[\bar{E}_{i, 10}, \bar{E}_{i, 20}, \bar{E}_{i, 30}, \ldots, \bar{E}_{i, 1440}\right]^{T}
$$

$N_{i}$ is the data number of the month $i$. The solar irradiation on reference days $j_{i}$ of each month $i$ is the closest to $\bar{E}_{i}$ [14].

\section{RESUltS AND ILLUSTRATION}

The values of $y_{\max }$ and $y_{\min }$ are chosen equal to one and zero respectively.

\section{A. Selection of interest variables and number of layers}

The correlation between the meteorological variables and solar irradiation forecasting accuracy over a $\Delta T$ horizon are presented in Table I. R denotes the correlation coefficient. The mean solar irradiation, maximum temperature and measurement time are choosed as the final input for the ANN. 
Table I.

INFLUENCE OF METEOROLOGICAL VARIABLES ON THE MEAN SOLAR IRRADIATION FORECASTING

\begin{tabular}{|c|c|}
\hline $\begin{array}{l}\text { interests variables } \\
\text { real time }(\mathrm{t})\end{array}$ & $\begin{array}{c}\mathrm{R}(\%) \\
\text { horizon }(t+\Delta T)\end{array}$ \\
\hline $\mathrm{P}$ & $05.21 \%$ \\
\hline Dn & $10.06 \%$ \\
\hline $\mathrm{Hm}$ & $43.76 \%$ \\
\hline $\mathrm{H}$ & $44.44 \%$ \\
\hline $\mathrm{h}$ & $52.41 \%$ \\
\hline $\mathrm{T}$ & $66.76 \%$ \\
\hline $\mathrm{Tm}$ & $67.27 \%$ \\
\hline $\mathrm{h}, \mathrm{T}$ & $67.81 \%$ \\
\hline h, Tm & $68.33 \%$ \\
\hline $\mathrm{T}, \mathrm{Tm}$ & $69.89 \%$ \\
\hline $\mathrm{h}, \mathrm{T}, \mathrm{Tm}$ & $94.66 \%$ \\
\hline Em & $98.09 \%$ \\
\hline T, Em & $98.11 \%$ \\
\hline Tm, Em & $98.11 \%$ \\
\hline he, Em & $98.12 \%$ \\
\hline T,Tm,Em & $98.21 \%$ \\
\hline h, T, Em & $98.36 \%$ \\
\hline h, Tm, Em & $98.36 \%$ \\
\hline h,T,Tm,Em & $98.36 \%$ \\
\hline $\mathrm{E}$ & $98.85 \%$ \\
\hline $\mathrm{E}, \mathrm{Em}$ & $98.85 \%$ \\
\hline $\mathrm{h}, \mathrm{E}$ & $98.86 \%$ \\
\hline $\mathrm{T}, \mathrm{E}$ & $98.88 \%$ \\
\hline $\mathrm{Tm}, \mathrm{E}$ & $98.88 \%$ \\
\hline T,Tm,E,Em & $99.01 \%$ \\
\hline $\mathrm{T}, \mathrm{Tm}, \mathrm{E}$ & $99.01 \%$ \\
\hline Tm,E,Em & $99.01 \%$ \\
\hline $\mathrm{h}, \mathrm{T}, \mathrm{E}$ & $99.06 \%$ \\
\hline h, Tm, E & $99.06 \%$ \\
\hline h,T,Tm,E & $99.06 \%$ \\
\hline h,E,Em & $99.1 \%$ \\
\hline h,Tm,E,Em & $99.1 \%$ \\
\hline h,T,Tm H,Hm,E,Em & $99.15 \%$ \\
\hline
\end{tabular}

Table II. ANN TRAINING PERFORMANCE

\begin{tabular}{|c|c|c|l|l|}
\hline $\begin{array}{c}\text { hori- } \\
\text { zons } \\
\text { (min) }\end{array}$ & training & vali- & test & $\begin{array}{l}\text { training } \\
\text { regression }\end{array}$ \\
\hline 30 & 0.98 & 0.981 & 0.982 & $y=0.96 x+0.0075$ \\
\hline 60 & 0.973 & 0.975 & 0.975 & $y=0.95 x+0.0093$ \\
\hline 90 & 0.968 & 0.970 & 0.969 & $\mathrm{y}=0.94 \mathrm{x}+0.012$ \\
\hline 120 & 0.965 & 0.961 & 0.968 & $\mathrm{y}=0.93 \mathrm{x}+0.013$ \\
\hline 150 & 0.959 & 0.954 & 0.959 & $\mathrm{y}=0.92 \mathrm{x}+0.014$ \\
\hline 180 & 0.957 & 0.956 & 0.954 & $\mathrm{y}=0.91 \mathrm{x}+0.015$ \\
\hline 210 & 0.953 & 0.950 & 0.949 & $\mathrm{y}=0.91 \mathrm{x}+0.017$ \\
\hline 240 & 0.950 & 0.948 & 0.945 & $\mathrm{y}=0.9 \mathrm{x}+0.018$ \\
\hline 270 & 0.947 & 0.947 & 0.941 & $\mathrm{y}=0.9 \mathrm{x}+0.019$ \\
\hline 300 & 0.945 & 0.943 & 0.942 & $\mathrm{y}=0.89 \mathrm{x}+0.02$ \\
\hline 330 & 0.941 & 0.938 & 0.942 & $\mathrm{y}=0.89 \mathrm{x}+0.021$ \\
\hline 360 & 0.941 & 0.936 & 0.940 & $\mathrm{y}=0.89 \mathrm{x}+0.021$ \\
\hline
\end{tabular}

\section{B. ANN training step}

$70 \%$ of the data are used for training ANN. Results are presented in tableII.

The first item in the Table II represents the forecasting horizons. It varies from 30 minutes to 360 minutes (06 hours). The second, third and fourth columns of Table II represent the correlation coefficient (R) for training, validation and test. The fifth column of table II represents the linear correlation of the training step from each forecasting horizon.

\section{ANN test step}

After the training step, $30 \%$ of data are used for ANN test. Figure 4 shows an overlay of the curves from the different forecasting horizons. Each curve represents a comparative study of the measured and forecasted values over a horizon of $30,60,90,120,150,180,210,240,300$ and 360 minutes respectively. Results show the steering coefficient of linear correlation lines, equal to 1 for horizons 30 to 180 minutes and 1.1 for horizons 210 to 360 minutes.

\section{Reference days}

Table III shows the reference days to be considered for each month. For example, June 08 is the reference day for June 2004.

The comparative study between measured and forecasted

Table III. REFERENCE DAYS ON EACH MONTH

\begin{tabular}{|l|l|l|l|l|l|}
\hline months & $\begin{array}{l}\text { June } \\
2004\end{array}$ & $\begin{array}{l}\text { July } \\
2004\end{array}$ & $\begin{array}{l}\text { August } \\
2004\end{array}$ & $\begin{array}{l}\text { november } \\
2004\end{array}$ & $\begin{array}{l}\text { December } \\
2004\end{array}$ \\
\hline $\begin{array}{l}\text { reference } \\
\text { days }\end{array}$ & 8 & 10 & 16 & 11 & 30 \\
\hline \hline months & $\begin{array}{l}\text { January } \\
2005\end{array}$ & $\begin{array}{l}\text { february } \\
2005\end{array}$ & $\begin{array}{l}\text { march } \\
2005\end{array}$ & $\begin{array}{l}\text { April } \\
2005\end{array}$ & $\begin{array}{l}\text { may } \\
2005\end{array}$ \\
\hline $\begin{array}{l}\text { reference } \\
\text { days }\end{array}$ & 6 & 25 & 19 & 7 & 2 \\
\cline { 1 - 3 } months & $\begin{array}{l}\text { June } \\
2005\end{array}$ & $\begin{array}{l}\text { july } \\
2005\end{array}$ & \multicolumn{4}{|l}{} & \\
\cline { 1 - 4 } $\begin{array}{l}\text { reference } \\
\text { days }\end{array}$ & 25 & 11 & & & \\
\cline { 1 - 4 }
\end{tabular}

values over the 360 horizon is presented for each reference days in Figure 5.

\section{STATISTICAL CRITERIA}

The ANN statistical criteria are presented in Table IV. The first column is the forecasting horizons. The second, third, fourth, and fifth columns indicate the correlation coefficient, mean squared error, normal squared error, and statistical time, respectively. A difference of 0.026 is observed between the correlation coefficient of the 30-minute and 360-minute horizons. Figure 6 presents

Table IV. FORECASTING HORIZONS' STATISTICAL CRITERIA

\begin{tabular}{|c|c|c|c|c|}
\hline forecasting horizons & $\mathrm{R}$ & RMSE & nRMSE & t-statistic \\
\hline 30 & 0.984 & 0.048 & 0.21 & 16.19 \\
\hline 60 & 0.981 & 0.054 & 0.24 & 22.50 \\
\hline 90 & 0.978 & 0.058 & 0.26 & 24.51 \\
\hline 120 & 0.976 & 0.061 & 0.27 & 31.05 \\
\hline 150 & 0.973 & 0.064 & 0.28 & 34.55 \\
\hline 180 & 0.971 & 0.066 & 0.29 & 35.23 \\
\hline 210 & 0.970 & 0.067 & 0.30 & 40.43 \\
\hline 240 & 0.969 & 0.067 & 0.30 & 41.16 \\
\hline 270 & 0.968 & 0.071 & 0.31 & 42.15 \\
\hline 300 & 0.965 & 0.072 & 0.32 & 46.33 \\
\hline 330 & 0.963 & 0.074 & 0.33 & 47.68 \\
\hline 360 & 0.961 & 0.075 & 0.33 & 46.21 \\
\hline
\end{tabular}

the correlation coefficient (R), root mean square error 

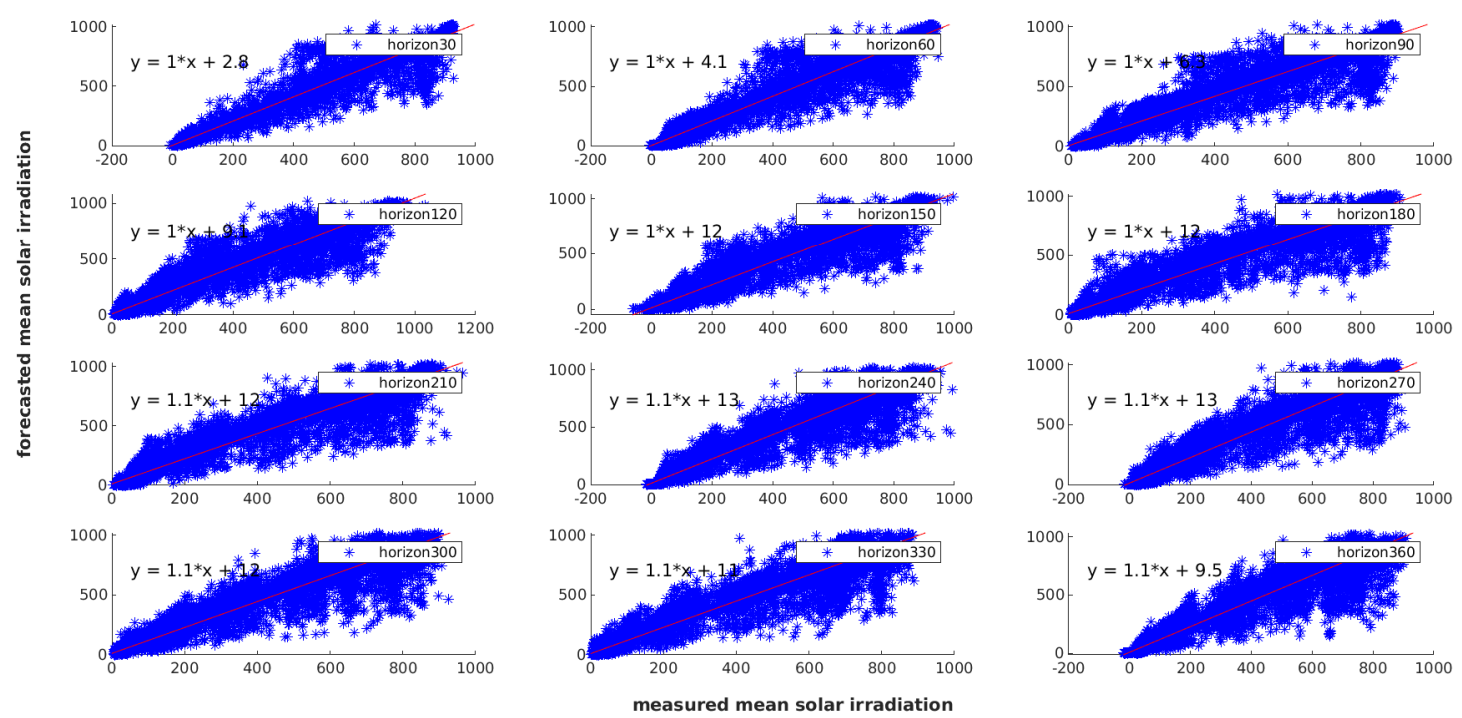

Figure 4. Solar irradiation versus the forecast horizons. Legend (blue): measured, (pink) predicted.
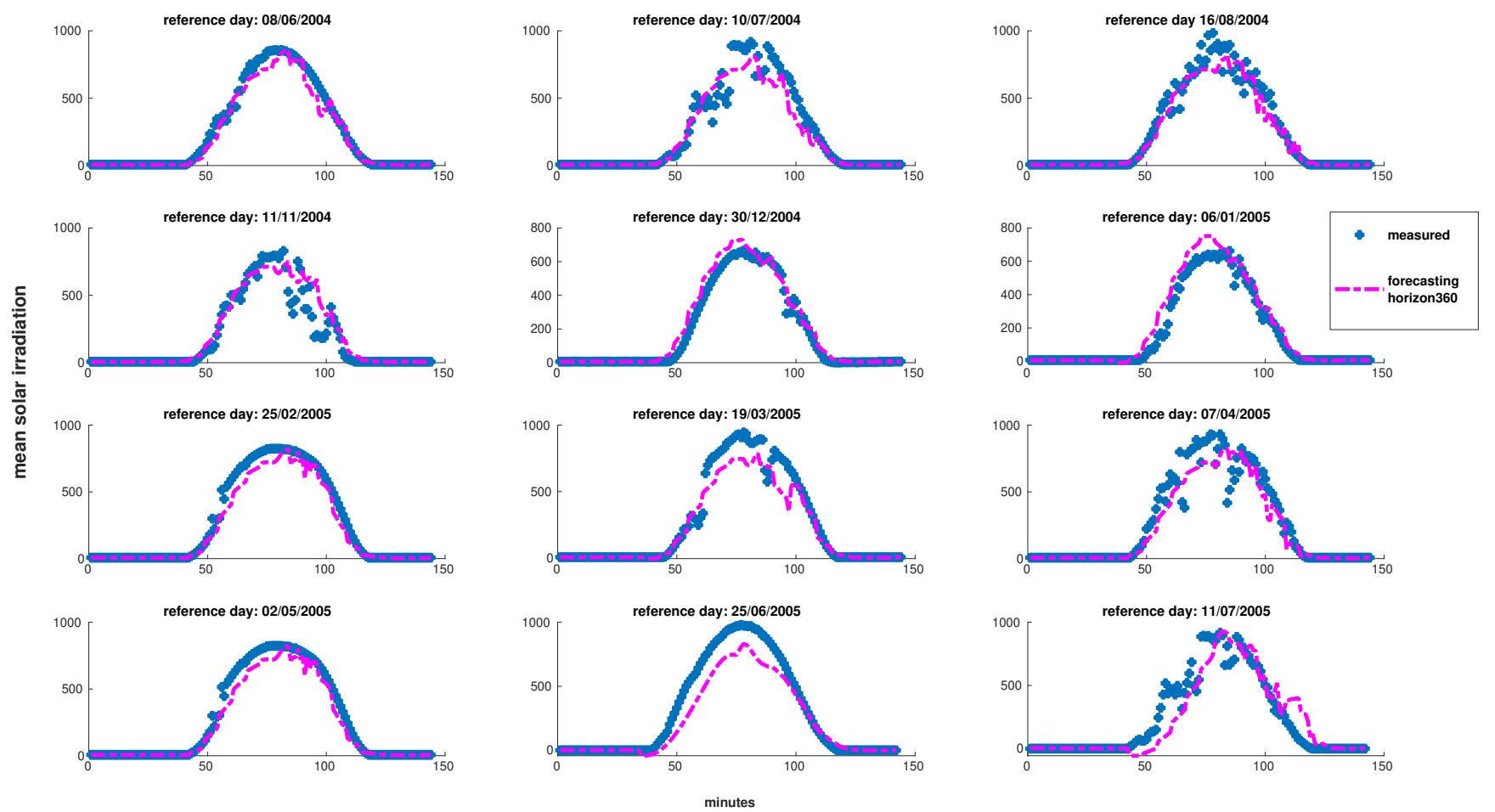

Figure 5. comparative studies between measured and forecasted values on reference days

(RMSE) and normal root mean square error (nRMSE) as a function of the forecasting horizons. There is little change in the RMSE and nRMSE as the forecasting horizon increases. The shorter the forecasting horizon, the lower the RMSE and nRMSE. Unlike RMSE and nRMSE, correlation coefficient decreases as the forecasting horizon increases. The statistical time increases as the forecasting horizon increases. 


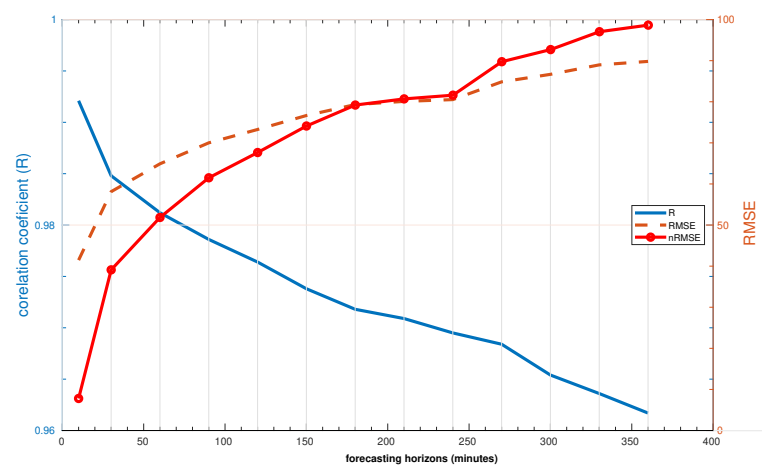

Figure 6. statistical criteria versus the forecasting horizons

\section{CONClusion AND PERspectives}

This work involved setting up and classifying short-term forecasting models for solar irradiation along several horizons in the north-west of Senegal. Several forecasting models are developed. The forecasting horizons are $30,60,90,120,150,180,210,240$, 270, 300, 330 and 360 minutes. The statistical criteria obtained allow to conclude that the solar irradiation forecasting can be extended over a six-hour horizon (360 minutes) with a correlation of $96 \%$. These results will allow investors in solar PV power plants to reduce the investment costs often allocated to data collection equipment (reduction of a large volume of historical data saved) and will also contribute to accurate solar energy planning.

The perspectives of this paper are:

- doing the same work in the other regions of Senegal,

- forecasting solar irradiation using only temperature data.

\section{ACKNOWLEDGMENT}

Authors would like to thank the CEA-MITIC and Eurasmus+ MIC funding programs, which enabled to carry out this work.

\section{REFERENCES}

[1] A. Ahmed and M. Khalid, "An intelligent framework for shortterm multi-step wind speed forecasting based on Functional Networks," Applied Energy, vol. 225, pp. 902-911, Sept. 2018.

[2] B. Bilal, K. H. Adjallah, K. Yetilmezsoy, M. Bahramian, and E. Kiyan, "Determination of wind potential characteristics and techno-economic feasibility analysis of wind turbines for Northwest Africa," Energy, vol. 218, p. 119558, Mar. 2021.
[3] J. C. Alberizzi, J. M. Frigola, M. Rossi, and M. Renzi, "Optimal sizing of a Hybrid Renewable Energy System: Importance of data selection with highly variable renewable energy sources," Energy Conversion and Management, vol. 223, p. 113303, Nov. 2020.

[4] M. F. Ndiaye, F. Guérin, D. Lefebvre, and P. A. Ndiaye, "Model Predictive Control and Generalized Adaptative PID for Load Sharing In Systems of Multiple Sources of Energy," IJARCCE, vol. 4, pp. 307-312, Oct. 2015.

[5] A. Kaur, L. Nonnenmacher, and C. F. Coimbra, "Net load forecasting for high renewable energy penetration grids," Energy, vol. 114, pp. 1073-1084, Nov. 2016.

[6] A. P. Marugán, F. P. G. Márquez, J. M. P. Perez, and D. RuizHernández, "A survey of artificial neural network in wind energy systems," Applied Energy, vol. 228, pp. 1822-1836, Oct. 2018.

[7] Z. Yang and J. Wang, "A hybrid forecasting approach applied in wind speed forecasting based on a data processing strategy and an optimized artificial intelligence algorithm," Energy, vol. 160, pp. 87-100, Oct. 2018.

[8] K. B. Debnath and M. Mourshed, "Forecasting methods in energy planning models," Renewable and Sustainable Energy Reviews, vol. 88, pp. 297-325, May 2018.

[9] F.-V. Gutierrez-Corea, M.-A. Manso-Callejo, M.-P. MorenoRegidor, and M.-T. Manrique-Sancho, "Forecasting shortterm solar irradiance based on artificial neural networks and data from neighboring meteorological stations," Solar Energy, vol. 134, pp. 119-131, Sept. 2016.

[10] M. Q. Raza, N. Mithulananthan, and A. Summerfield, "Solar output power forecast using an ensemble framework with neural predictors and Bayesian adaptive combination," Solar Energy, vol. 166, pp. 226-241, May 2018.

[11] R. Jovanović, A. A. Sretenović, and B. D. Živković, "Ensemble of various neural networks for prediction of heating energy consumption," Energy and Buildings, vol. 94, pp. 189-199, May 2015.

[12] A. K. Yadav, H. Malik, and S. Chandel, "Selection of most relevant input parameters using WEKA for artificial neural network based solar radiation prediction models," Renewable and Sustainable Energy Reviews, vol. 31, pp. 509-519, Mar. 2014.

[13] E. Mboumboue, D. Njomo, M. L. Ndiaye, P. A. N'diaye, M. F. Ndiaye, and A. K. Tossa, "On the applicability of several conventional regression models for the estimation of solar global radiation component in Cameroon and Senegal subSaharan tropical regions," Journal of Renewable and Sustainable Energy, vol. 8, p. 025906, Mar. 2016.

[14] M. F. Ndiaye, A. K. Mbodji, O. Cisse, E. Mboumboue, and M. L. Ndiaye, "Prévision à court terme du potentiel éolien par la méthode de prédiction linéaire : application au site de Gandon au Sénégal,” p. 8, 2016.

[15] W. M. NKOUNGA, M. F. NDIAYE, M. L. NDIAYE, O. CISSE, M. BOP, and A. SIOUTAS, "Short-term forecasting for solar irradiation based on the multi-layer neural network with the Levenberg-Marquardt algorithm and meteorological data: application to the Gandon site in Senegal," in 2018 7th International Conference on Renewable Energy Research and Applications (ICRERA), pp. 869-874, Oct. 2018. ISSN: 25726013.

[16] A. Mbaye, J. Ndong, M. NDiaye, M. Sylla, M. Aidara, M. Diaw, M. NDiaye, P. A. Ndiaye, and A. Ndiaye, "Kalman filter model, as a tool for short-term forecasting of solar 
potential: case of the Dakar site," E3S Web of Conferences, vol. 57, p. 01004, 2018.

[17] A. Mbaye, M. Ndiaye, D. Ndione, M. Sylla, M. Aidara, M. Diaw, V. Traoré, A. Ndiaye, and P. Ndiaye, "ARMA model for short-term forecasting of solar potential: application to a horizontal surface on Dakar site," 2019. type: dataset.

[18] O. Adeoye and C. Spataru, "Modelling and forecasting hourly electricity demand in West African countries," Applied Energy, vol. 242, pp. 311-333, May 2019.

[19] A. Sarr, C. M. F. Kebe, and A. Ghennioui, "Comparative approach for global solar estimation in four typical Senegalese climatic zones," in 2020 5th International Conference on Renewable Energies for Developing Countries (REDEC), (Marrakech, Morocco, Morocco), pp. 1-6, IEEE, June 2020.

[20] A. MBAYE, M. L. NDIAYE, J. Ndong, and P. A. S. Ndiaye, "Impact of Meteorological Parameters on Short-Term Forecasting: Application to the Dakar Site," in 2019 IEEE 2nd International Conference on Power and Energy Applications (ICPEA), pp. 227-231, Apr. 2019.

[21] E. F. Alsina, M. Bortolini, M. Gamberi, and A. Regattieri, "Artificial neural network optimisation for monthly average daily global solar radiation prediction," Energy Conversion and Management, vol. 120, pp. 320-329, July 2016.

[22] S. M. Mousavi, E. S. Mostafavi, and P. Jiao, "Next generation prediction model for daily solar radiation on horizontal surface using a hybrid neural network and simulated annealing method," Energy Conversion and Management, vol. 153, pp. 671-682, Dec. 2017. 